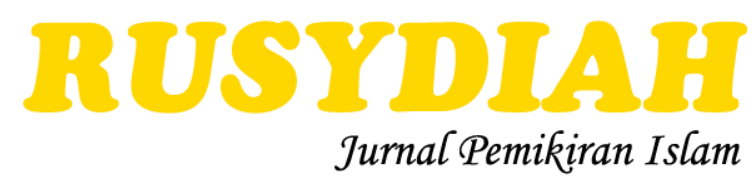

Volume 1 Nomor 1, Juni 2020

ISSN: 2723-4894 (cetak), ISSN: 2723-4886 (daring)

DOI: https:// doi.org/10.35961/rsd.v1i1.127

\title{
TASAWUF DAN PERUBAHAN SOSIAL: Kajian Tokoh Umar bin Abdul
}

\author{
Ning Ratna Sinta Dewi \\ STAIN Sultan Abdurraman Kepulauan Riau \\ ningratna_sinta@stainkepri.ac.id
}

\begin{abstract}
Abstrak
Tasawuf sosial adalah tasawuf yang tidak hanya mementingkan kesalehan individu saja. Akan tetapi tasawuf sosial ini juga peka dan terlibat dalam sebuah gerakan untuk melakukan suatu perubahan dalam kehidupan sosial. Beranjak dari sebuah tradisi keilmuwan seperti yang ada di pesantren dan perguruan tinggi Islam lainnya. Adanya usaha untuk mencari jalan terhadap perubahan tasawuf yang berhubungan dengan kehidupan sosial yang ada di Indonesia khususnya. Model penampilan dari tasawuf di masa modern seperti sekarang ini tidak harus menjauhi kekuasaan, tetapi justru harus masuk dan berbaur ditengah-tengah pergulatan politik dan kekuasaan. Karena sikap menjauhi kekuasaan menunjukkan sikap lemah dan ketidakberdayaan. Dengan kata lain dapat dijelaskan, bahwa tasawuf sosial bukanlah tasawuf yang bersifat tertutup dan isolatif, melainkan tasawuf ini akan aktif ditengah-tengah pembangunan yang terjadi di masyarakat, bangsa dan juga negara. Yang mana menjadi tuntutan dan tanggungjawab sosial dari tasawuf tersebut. Tasawuf yang diharuskan tidak harus uzlah dari keramaian, sebaliknya tasawuf harus memiliki peran dan aktif dalam kehidupam secara total, baik dalam bidang sosial, politik, ekonomi ataupun yang lainnya. Oleh karena itu, peran sufi harus bersikap lebih empirik, pragmatis dan fungsional dalam menyikapi dan memandang kehidupan secara nyata.
\end{abstract}

Katakunci: Tasawuf; modern; sosial.

\begin{abstract}
Social Sufism is sufism that isi not only concerned with individual piety. However, social sufism is also sensitive and involved in a movement to make changes in social life. Moved from a scientific tradition such as those in Islamic boarding schools and onther Islamic Universities. There are efforts to find ways to change sufism related to social life in Indonesia in particular. The appearance model of sufism in modern times like today does not have to stay away from power, but rather it must enter and mingle in the midst of political and power struggles. Because the attitude away from power shows a weak attitude and helplessness. In other words it can be explained, that social sufism is not sufism which is closed and isolated, but sufism will be active in the midst of development that occurs in society, nation, and also te country. Which becomes te demands and social responsibility of the sufism.
\end{abstract}

Rusydiah: Jurnal Pemikiran Islam, Vol. 1, No. 1, Juni 2020 
Sufism is required not uzlah from the crowd, o the contrary sufism must have a role ad be aactive in total life, both in the social, political, economic, and other fields. Therefore, the role of Sufis must be more empirical, pragmatic, and functional in addressing real life.

Keywords: Sufism; Modern; Social.

\section{PENDAHULUAN}

Berdasarkan catatan sejarah keislaman, pada masa Rasulullah SAW penggunaan istilah tasawuf belum dikenal, akan tetapi dalam praktiknya sudah diterapkan hanya saja belum terlambangkan sebagai suatu ilmu dalam Islam. Istilah tasawuf dipakai pada abad ke- $2 \mathrm{H},{ }^{1}$ dan ada juga yang mengatakan istilah tasawuf baru terdengar sekitar abad ke-3 $\mathrm{H}^{2}{ }^{2}$

Di era modern seperti sekarang ini, ajaran dari tasawuf dapat digunakan sebagai solusi dalam meghadapi berbagai macam persoalan dalam kehidupan umat manusia, yang hidupnya serba materialis, hedonis, sekular, bahkan dengan kehidupan yag secara finansial semakin susah dan juga ditambah lagi degan persoalan psikologi dari manusia yang semakin mengalami perubahan yang sangat mendekati keburukan. Oleh karena itu, tasawuf ini sangat dibutuhkan umat manusia.

Menelaah terhadap fenomena tersebut, wacana dalam keislaman mengaitkan istilah tasawuf dengan ilmu sosial, dan untuk mengetahui sejauh mana tasawuf itu sangat berpengaruh dalam kehidupan sosial manusia, untuk itu makalah ini akan memaparkan tentang hubungan "tasawuf dengan perubahan sosial", yang mana akan memberikan jawaban terhadap perubahan sosial yang terjadi di masyarakat.

\section{METODE}

Metode penelitian yang digunakan dalam penulisan ini adalah metode studi kepustakaan. Yakni suatu metode yang menghimpun dan memperoleh informasi yang relevan dan sesuai dengan topik yang dibahas. Informasi tersebut diperoleh dari buku-buku, karya ilmiah, tesis, disertasi, ensiklopedia, internet, dan

${ }^{1}$ Pada Abad II H, muncullah taríqah al-Sûfiyyah yaitu tarekat yang diamalkan oleh para sufi ,Azyumardi Azra, Ensiklopedi Tasawuf, Jilid III, (Bandung: Angkasa, Tt), h. 1290.

2Pada Abad III H, dapat dikatakan bahwa tasawuf sebagai sebuah disiplin ilmu sudah tersusun, sebagai jalan mengenal Allah (ma'firah) yang sebelumnya hanya dikenal sebagai jalan ibadah saja. Dan pada saat itu muncul banyak tokoh sufi seperti Abû Yazîd al-Bustâmî ,Azyumardi Azra, Ensiklopedi Tasawuf, h. 1292. 
sumber-sumber pendukung lainnya. Studi kepustakaan ini memanfaatkan semua informasi dan pemikiran-pemikiran yang relevan dengan penulisan jurnal ini. Studi kepustakaan ini merupakan kegiatan yang harus diakukan secara terus menerus pada saat penulisan jurnal, yang bertujuan untuk menemukan informasiinformasi yang berkaitan dengan penulisan jurnal

\section{HASIL DAN PEMBAHASAN}

\section{A. Pengertian Tasawuf dan Sosial}

Tasawuf berasal dari bahasa Arab, yaitu dari kata tashawwafa, yatashawwafu, tashawwufan, yang memiliki arti bulu domba (Shuf), barisan (Shaf), jernih (Shafa), pinggiran mesjid Nabawi yang ditempati oleh sebagian sahabat Rasulullah SAW (Shuffah). Hal tersebut berdasarkan pemikiran para sufi yang beranekaragam yang memberikan pengertian secara etimologi terhadap kata tasawuf. ${ }^{3}$

Secara etimologi, kata tasawuf seperti yang dikemukakan oleh para tokoh juga sangat beragam, antara lain menurut Ibn Arabi, tasawuf diartikan sebagai suatu proses dalam hal menaktulisasikan potensi akhlak Allah SWT yang ada di dalam diri manusia, dan menjadikan sebagai akhlak bagi manusia tersebut. ${ }^{4}$

Syekh Abul Hasan Asy-Syadzili, ${ }^{5}$ memberikan defenisi terhadap tasawuf yaitu: sebagai suatu "praktik atau latihan diri melalui cinta yang mendalam dan juga ibadah untuk mengembalikan diri kepada jalan Tuhan".

Mengingat adanya usaha untuk mengembangkan tasawuf sebagai suatu ilmu. Maka dari itu, harus adanya usaha untuk melakukan perubahan. Tasawuf yang berperan sebagai sarana untuk mendekatkan diri yang sedekat-dekatnya dengan Allah SWT, baik melalui peningkatan dalam ibadah. Karena itu, akibat dari sikap tersebut tasawuf hanya dipandang sebagai suatu kehidupan yang hanya memandang dalam hal ibadah saja, tanpa mempunyai kepedulian terhadap sesama manusia. Dapat dicontohkan dalam hal bersikap zuhud, ${ }^{6}$ yang

${ }^{3}$ Departemen Pendidikan dan Kebudayaan, Kamus Besar Bahasa Indonesia, h. 500.

${ }^{3}$ M. Amin Syukur, Tasawuf Sosial, (Yogyakarta: Pustaka Pelajar, 2004), h. v.

${ }^{3}$ M. Amin Syukur, Tasawnf Sosial, h. 24. Azyumardi Azra, Ensiklopedi Tasawnf, h. 1289.

${ }^{4} \mathrm{Ibn}$ 'Arabi, Fusûs al-Hikam, (Beirut: Dâr al-Kitab al-'Arabi, Tt).

${ }^{5}$ Syek Abul Hasan Asy-Syadzili adalah seorang sufi besar yang berasal dari Afrika Utara.

${ }^{6}$ Zuhud diartikan sebagai sikap dimana tidak adanya ketergantungan hati terhadap hal-hal keduniawian (harta benda), serta hal-hal lain yang dapat menjadikan seseorang itu jauh dari Tuhan-Nya, dalam Azyumardi Azra, Ensiklopedi Tasawuf, h. 1287. 
selama ini hanya dianggap sebagai sikap meninggalkan dunia (sandanng, pangan, papan dan biaya pedidikan). Selain itu, apabila seseorang telah mencapai tingkatan tertinggi dari tasawuf, maka orang tersebut bukan hanya lupa akan kehidupan sosial, dirinya sendiripun bahkan dia lupakan karena hanya Allah SWT sajalah yang menjadi perhatiannya. Sehingga dengan begitu, perilaku dari tasawuf tersebut dipandang semakin menjauhi kehidupan sosial.

Sedangkan kata sosial dalam Kamus Besar Bahasa Indonesia, diartikan sebagai sesuatu yang menyangkut aspek dari kehidupan masyarakat. Sosial atau yang dikenal dengan sosiologi merupakan suatu ilmu yang mempelajari tentang masyarakat yang berhubungan dengan perilaku dari masyarakat. ${ }^{7}$ Tasawuf sosial adalah tasawuf yang tidak hanya mementingkan kesalehan individu saja. Akan tetapi tasawuf sosial ini juga peka dan terlibat dalam sebuah gerakan untuk melakukan suatu perubahan dalam kehidupan sosial.

Beranjak dari sebuah tradisi keilmuwan seperti yang ada di pesantren dan perguruan tinggi Islam lainnya. Adanya usaha untuk mencari jalan terhadap perubahan tasawuf yang berhubungan dengan kehidupan sosial yang ada di Indonesia khususnya. ${ }^{8}$ Model penampilan dari tasawuf di masa sekarang ini tidak harus menjauhi kekuasaan, tetapi justru harus masuk dan berbaur di tengah-tengah pergulatan politik dan kekuasaan. Karena sikap menjauhi kekuasaan menunjukkan sikap lemah dan ketidakberdayaan. ${ }^{9}$

Dengan kata lain dapat dijelaskan, bahwa tasawuf sosial bukanlah tasawuf yang bersifat tertutup dan isolatif, melainkan tasawuf ini akan aktif ditengah-tengah pembangunan yang terjadi di masyarakat, bangsa dan juga negara. Yang mana menjadi tuntutan dan tanggungjawab sosial dari tasawuf tersebut.

Tasawuf yang diharuskan tidak harus uzlah dari keramaian, sebaliknya tasawuf harus memiliki peran dan aktif dalam kehidupam secara total, baik dalam bidang sosial, politik, ekonomi ataupun yang lainnya. Oleh karena itu, peran sufi harus bersikap lebih empirik, pragmatis dan fungsional dalam menyikapi dan memandang kehidupan secara nyata. ${ }^{10}$

\section{B. Sufi Sebagai Agen Perubahan Sosial}

\footnotetext{
${ }^{7}$ Departemen Pendidikan dan Kebudayaan, Kamus Besar Bahasa Indonesia, h. 500.

${ }^{8}$ M. Amin Syukur, Tasawnf Sosial, (Yogyakarta: Pustaka Pelajar, 2004), h. v.

${ }^{9}$ M. Amin Syukur, Tasawnf Sosial, h. 24.

${ }^{10}$ M. Amin Syukur,..., h. 28.
} 
Kehadiran tasawuf sebagai dampak dari amalan esoterik dari keagamaan memiliki fungsi sebagai pemberi nilai spiritual bagi perilaku keagamaan dan juga perilaku sosial dari umat Islam. Nilai moralitas tasawuf muncul dalam kehidupan manusia adalah sebagai penyeimbangan dari sebahagian ataupun seluruh pemikiran intelektual dari manusia yang berkaitan dengan eksistensinya dalam mencapai ketenangan. Oleh karena itu, perlunya peralihan tasawuf dalam kehidupan sosial. Tasawuf dalam praktek sosialnya dituntut agar mampu menunjukkan diri sebagai rahmat bagi masyarakat, artinya tasawuf ini mampu menjalankan peranannya baik dalam kehidupan keseharian yang bersifat keduniawian ataupun dalam kehidupan sosial. ${ }^{11}$

Di era modern seperti sekarang ini, para sufi dituntut untuk bisa melakukan perubahan terhadap ajaran-ajaran tasawuf. Dimana ajaran tasawuf yang awalnya hanya mementingkan diri sendiri, saat ini para sufi diharapkan mampu menjadi agen yang dapat menjembatani perkembangan tasawuf itu sendiri, dan kenyataanya harus adanya pengaktualisasi dan sosialisasi yang dilakukan para sufi di masyarakat. Sikap menutup diri dari lingkungan sosial dalam hal hanya untuk mendapatkan kenikmatan rohani saja, adalah merupakan sikap egois yang dilakukakan oleh para sufi. Di saat kemajuan peradaban dan kebudayaan serta perkembangan teknologi, hal ini merupakan sikap yang tidak pantas dilakukan. Karena sikap tersebut akan menjadikan manusia (para sufi) terisolasi ditengah arus kemajuan zaman.

Pengasingan diri yang dilakukan sufi semestinya tidak menjauhi ataupun menghindari pergaulan sosial. Maksud dari pengasingan diri yang dilakukan adalah dengan cara mengasingkan hati dari kesibukan dan ketergantungan pada persoalan duniawi semata. Seorang sufi tidak harus diartikan anti keduniawian dan juga anti sosial. Akan tetapi, seorang sufi harus mampu menjaga jarak dengan hal-hal yang bersifat kematerian dengan kata lain ajaran tasawuf itu dapat dijadikan sebagai alat untuk mengontrol seluruh aktivitas dari kegiatan, ucapan dan juga perilaku yang dilakukan baik oleh sufi itu sendiri ataupun orang lain. ${ }^{12}$

\section{Tasawuf dan Perubahan Sosial}

Tasawuf dan perubahan sosial harus dapat dikembangkan dalam kehidupan masyarakat, maka dari itu harus dipahami budaya yang ada dan

${ }^{11}$ www.al-wiraja.blogspot.com/2013/02/tasawuf dan politik.

${ }^{12}$ www.al-wiraja.blogspot.com/2013/02/tasawuf dan politik. 
berkembang di masyarakat tersebut. Dimana tasawuf yang dianggap memiliki sikap egois dengan mengedepankan ataupun menunjukkan simbol-simbol seperti memakai jubah, berjanggut panjang sekiranya harus diartikan ulang kembali. Tasawuf harus mampu mengakomodasikan budaya lokal yang ada, terutama di daerah yang sangat kental budayanya. Apabila tasawuf tidak didukung oleh budaya lokal yang ada, maka tasawuf akan dianggap tidak berbanding lurus dengan budaya yang telah ada, maka ajaran tasawuf tidak akan diterima oleh masyarakat setempat. Selain itu, persoalan kebudayaan yang ada di masyarakat, ada yang dikatakan sebagai budaya yang baik dan ada juga dikatakan sebagai budaya yang rusak dan harus diperbaik sedikit demi sedikit sehingga akan terarah kearah yang lebih baik. Adanya toleransi terhadap budaya lokal ini dapat menjadi jembatan dalam keberhasilan dari tasawuf dalam melakukan perubahan-perubahan sosial yang ada di masyarakat, terutama masyarakat yang budaya lokalnya masih sangat kuat.

Menurut Amin Syukur, "mengingat persoalan sosio-kultur masyarakat yang senantiasa berkembang sehingga tasawuf dituntut untuk mampu menjadi solusi bagi persoalan-persoalan masyarakat yang muncuk dewasa ini, terutama pada abad sekarang ini, dimananya eranya adalah era modernisasi", ${ }^{13}$ sehingga dalam tasawuf sosial dikatakan bahwa posisi Islam ditengah-tengah deraan lajunya kemajuan sains dan teknologi. Dalam menghadapi masyarakat modern yang menempatkan pertimbangan akal ataupun rasio sebagai kekuatan utama, dan Islam haruslah ditawarkan secara utuh dan fungsional". ${ }^{14}$

Selain itu, tasawuf sosial yang diharapkan adalah tasawuf yang tidak memisahkan antara hakikat dan syari'at, dan juga tidak hanya mempersoalkan kehidupan duniawi, melainkan antara kehidupan duniawi dan ukhrawi juga harus berdampingan (tidak ada terjadinya pemisahan). Tasawuf sosial seperti yang telah dikemukakan diawal, adalah tasawuf yang tidak bersifat isolatif. Akan tetapi tasawuf sosial harus aktif ditengah-tengah pembangunan

${ }^{13}$ Modernisasi ditandai dengan beberapa ciri pokok; pertama, berkembangnya mass culture karena pengaruh media massa sehingga budaya tidak lagi bersifat lokal, melainkan bersifat nasional (bukan global). Kedua, tumbuhnya sikap-sikap yang lebih mengakui kebebasan dalam bertindak, dimana manusia bergerak menuju perubahan-perubahan kearah yang lebih maju, bahkan adanya sikap untuk dapat menaklukan alam. Dimana hal ini membuat manusia menjadi lebih leluasa dan bahkan merasa berkuasa dan menjadi serakah. Ketiga, timbulnya kecenderungan berpikir rasional, meskipun pemikir irasional tidak dapat dihilangkan sama sekali dalam kehidupan manusia, akan tetapi sebagai kehidupan manusia diatur oleh aturan yang bersifat rasional. Keempat, tumbuhnya sikap hidup yang materialistik, artinya semua hal diatur dan dinilai berdasarkan ukuran ekonomi. Kelima, meningkatnya laju urbanisasi.

${ }^{14}$ M. Amin Syukur,..., h. vi. 
masyarakat, bangsa dan Negara sebagai tuntutan tanggung jawab sosial tasawuf di abad sekarang ini.

\section{Kajian Tokoh dan Kawasan}

Tasawuf dalam catatan sejarah sering sekali dianggap sebagai faktor dari penyebabab kemundurannya umaat Islam. Sejak kemunculannya, tasawuf telah menuai banyak kritik, bahkan penolakannya sebagai bagian terpenting dari ajaran Islam. salah satu yang menjadi sasaran dari kritikan terhadap tasawuf adalah tentang ajaran asketisme dan zuhud yang sangat tidak relevan dengan kemajuan zaman pembangunan. Tasawuf bahkan dikatakan sebagai penghambat umat Islam untuk maju dan berkembang. Dimana tasawuf hanya suatu sikap yang hanya mengajak manusia untuk "terhanyut-hanyut di alam lain (esoterisme) tanpa peduli dengan keadaan sosial politik yang ada" ${ }^{15}$

Catatan sejarah perpustakaan sufi, mengemukakan bahwa dalam persoalan sosial-politik banyak sufi yang memberikan sumbangan yang sangat besar dalam pengembangan berbagai bidang ilmu pengetahuan dan juga kemajuaan peradaban. Misalnya pada dinasti Safawiyah. Dinasti Syafawi berdiri sejak tahun 1503-1722 M. Dinasti ini lahir dari sebuah gerakkan tarekat yang berdiri di Ardabil, sebuah kota di Azerbaijan. Tarekat ini diberi nama tarekat Syafawi, yang diambil dari nama pendirinya Safi Al-Din dan nama Syafawi terus dipertahankan sampai tarekat ini menjadi gerakan politik. ${ }^{16}$

Selain itu, dalam pengembangan ilmu pengetahuan, para sufi ikut berpartisipasi langsung dalam membangun universitas ataupun madrasah, dan juga pusat-pusat bahasa Arab. Hal ini merupakan usaha dari pengembangan dibidang pendidikan dan perubahan sosial. ${ }^{17}$

Tokoh yang akan dibahas dalam perubahan sosial yang dilakukannya adalah seorang yang dikenal sebagai sufi, yang dalam catatan sejarah juga menjadi seorang pemimpin serta memiliki sikap zuhud dan juga mampu menjalankan pemerintahan tanpa melupakan urusan ukhrawi dalam kehidupannya, adalah Umar bin Abdul Aziz.

${ }^{15}$ Ahmad Syafii Maarif, Islam: Kekuatan Doktrin dan Keagamaan Umat, (Yogyakarta: Pustaka Pelajar, 1997), h. 49.

${ }^{16}$ Badri Yatim, Sejarah Peradaban Islm, Cet VII, (Jakarta: Raja Grafindo Persada, 2000, hlm. 138.

${ }^{17}$ Nurcholish Madjid, Islam Agama dan Peradaban: Membangun Makna Relevansi Doktrin Islam Dalam Sejarah, (Jakarta: Paramadina, 1995), h. 96. 


\section{Umar bin Abdul Aziz}

1. Biografi

Umar bin Abdul Aziz memiliki nama lengkap Abu Muhammad bin Abdullah bin Abdul Hakam, lahir di kota Madinah pada tahun 63 H.18 Ayahnya adalah seorang gubernur di Mesir. Akan tetapi karena Umar dan ibunya tinggal di Madinah. Pada saat ibunya hendak menjumpai ayahnya, Umar dititipkan oleh pamannya yang bernama Abdullah bin Umar. Dia menjalani pendidikannya di Madinah dengan para ulama-ulama yang kompeten yang ada di Madinah.

Beberapa riwayat mengatakan Umar dibiarkan besar dan belajar di Madinah adalah karena keinginan ayahnya untuk menjadikan Umar sebagai pemimpin layaknya Khalifah Umar bin Khattab. Sehingga ayahnya menyuruhnya untuk tetap tinggal dan menyelesaikan pendidikannya di Madinah. Dan dia dijadikan gubernur di kota tersebut sejak tahun 86 H-93 H. ${ }^{19}$

2. Sikap yang dilakukannya

Tatkala Umar bin Abdul Aziz menjadi gubernur di Madinah, segala urusan yang dia jalankan selalu dikonsiltasikannya dengan para ulamaulama yang ada di sana, seperti Urwah bin Zubair, Ubaidullah bin Abdullah bin Utbah, Abu Bakar bin Abdur Rahman bin Harits, dan beberapa ulama terkemuka lainnya.

Selain itu, sikap mulia yang ditunjukan Umar pada saat menerima tampuk kepemimpinan. Selain itu sikap berani yang ditunjukkanya pada saat adanya para penguasa yang melakukan kesalahan, maka Umar dengan beraninya menunjukkan sikap kepemimpinan yang bijaksana, tegas dan adil dalam hal menegakkan kebenaran. Umar juga akan mengganti para gubernur jika mereka tidak melakukan tugasnya dengan baik.

Umar bin Abdul Aziz sadar bahwa kepemimpinan adalah merupakan titipan dan bukan hadia. Karena itu, dia tidak menjadikannya lebih mulia ataupun berkedudukan, sebaliknya hal tersebut merupakan suatu ujian yang sangat berat baik dirinya. Prinsip yang dipegangnya adalah, apabila titipan

${ }^{18}$ Abdul Aziz bin Abdullah al-Humaidi, Umar bin Abdul Aziæ: Sosok Pemimpin Zubud dan Khalifah Cerdas, Cet I, (Solo: Tinta Media, 2015), h. 4.

${ }^{19}$ Abdul Aziz bin Abdullah al-Humaidi, Umar bin Abdul Aziz: Sosok Pemimpin Zubud dan Khalifah Cerdas, h. 6. 
tersebut dijalankan dengan sebaiknya maka akan mendapatkan ridha Allah SWT dan akan menjadi sebuah kenikmatan, serta akan mendapat naungan kelak di akhirat. Dan apabila titipan tersebut tidak dijalankan dengan adil, maka petaka yang akan terjadi pada dirinya.

Adapun prinsip-prinsip kepemimpinan yang dijalankan oleh Umar bin Abdul Aziz adalah:

a) Mengembalikan hak orang lain yang telah dirampas oleh penguasapenguasa sebelumnya.

b) Tegas dalam menegakkan kebenaran, bertanggung jawab dan berlaku adil.

c) Tidak gentar menghadapi kelompok lawan meskipun jumlah lawannya banyak.

d) Tidak merasa takut kepada siapapun, kecuali kepada Allah SWT semata.

e) Tidak ada satu kekuatan pun yang mampu menghalangi derap langkahnya. Sebeb, hatinya hanya percaya kepada Allah SWT sehingga setan pun tidak mampu menggodanya dengan tipuan harta, tahta, dan dunia. $^{20}$

Prinsip-prinsip yang dipegang oleh Umar bin Abdul Aziz juga diterapkannya dalam nilai-nilai tasawuf yang ada pada dirinya dan dengan sikap tersebut Umar berusaha untuk melakukan perubahan sosial yang ada di masyarakat, antara lain:

a) Arahan berkomunikasi dan berteman. Dimana Umar bin Abdul Aziz memberikan arahan kepada generasi umat Islam untuk memiliki akhlak yang lurus, serta memiliki sikap tawadu' yang harus ditanamkan dalam diri umat Islam.

b) Penolakkan Umar bin Abdul Aziz terhadap paham nepotisme kesukuan, sikap tersebut merupakan sikap yang akan memperkuat persaudaraan tanpa harus membedakan suku yang ada pada masyarakat.

c) Selalu bersyukur dalam segala hal, merupakan keutamaan bagi Umar bin Abdul Aziz, karena dengan bersyukur masyarkat akan mampu menjauhi sikap takabbur dan riya yang ada di dalam kehidupan mereka.

d) Sikap mendidik yang dilakukan oleh Umar bin Abdul Aziz terhadap masyarakat yang ada di desa, sehingga masyarakat diajaka untuk belajar perkara-perkara Islam, dan mengajak mereka memeluk agama Islam

\footnotetext{
${ }^{20}$ Abdul Aziz bin Abdullah al-Humaidi,..., h. 34.
} 
secara perlahan-lahan. Dan pendidikan yang dilakukan oleh Umar dan juga sahabatnya tidak meminta bayaran apapun kepada masyarakat, karena tujuan mereka adalah mengembangankan ajaran-ajaran Islam kepada seluruh manusia.

e) Selain itu, Umar bin Abdul Aziz giat dalam persoalan reformasi sosial, yakni berkaitan dengan pemberantasan penyakit masyarakat dalam berbagai bentuk kemungkaran.

f) Adanya sikap netral yang dilakukan oleh Umar bin Abdul Aziz tatkala terjadi perselisihan antara sahabat, dan juga kegigihannyaa dalam membantu orang yang lemah.

g) Adanya upaya untuk mempererat hubungan antara lapisan masyarakat, yaitu dengan cara memberikan hak dan kesempatan kepada siapapun untuk dapat berinteraksi dengan orang lain tanpa harus memandang status sosial yang dimiliki. Karena Umar berusaha untuk menghilangkan perbedaan yang terjadi di masyarakat. Sehingga tidak adanya rasa minder bagi kaum yang lemah. Hal ini dilakukan Umar dalam hal untuk meningkatkan taraf ekonomi masyarakat. ${ }^{21}$

\section{KESIMPULAN}

Tasawuf sosial adalah tasawuf yang tidak hanya mementingkan kesalehan individu saja. Akan tetapi tasawuf sosial ini juga peka dan terlibat dalam sebuah gerakan untuk melakukan suatu perubahan dalam kehidupan sosial. Tasawuf dalam praktek sosialnya dituntut agar mampu menunjukkan diri sebagai rahmat bagi masyarakat, artinya tasawuf ini mampu menjalankan peranannya baik dalam kehidupan keseharian yang bersifat keduniawian ataupun dalam kehidupan sosial. Model penampilan dari tasawuf di masa sekarang ini tidak harus menjauhi kekuasaan, tetapi justru harus masuk dan berbaur ditenga-tengah pergulatan politik dan kekuasaan. Karena sikap menjauhi kekuasaan menunjukkan sikap lemah dan ketidakberdayaan.

Catatan sejarah perpustakaan sufi, mengemukakan bahwa dalam persoalan sosial-politik banyak sufi yang memberikan sumbangan yang sangat besar dalam pengembangan berbagai bidang ilmu pengetahuan dan juga kemajuaan peradaban. Misalnya pada dinasti Safawiyah. Selain itu, seorang yang dikenal sebagai sufi, yang dalam catatan sejarah juga menjadi seorang pemimpin serta

\footnotetext{
${ }^{21}$ Abdul Aziz bin Abdullah al-Humaidi,..., h. 100-113.
} 
memiliki sikap zuhud dan juga mampu menjalankan pemerintahan tanpa melupakan urusan ukhrawi dalam kehidupannya, adalah Umar bin Abdul Aziz, yang selain memiliki dan menerapkan sikap-sikap kehidupan para sufi, dia juga mampu mengembangkan ajaran tasawuf dan menerapkannya dalam kehidupan sosial di masyarakat.

\section{DAFTAR PUSTAKA}

Abdul Aziz bin Abdullah al-Humaidi, Umar bin Abdul Aziz, Sosok Pemimpin Zuhud dan Khalifah Cerdas, Cet I, (Solo: Tinta Media, 2015)

Ahmad Syafi Maarif, Islam: Kekuatan Doktrin dan Keagamaan Umat, (Yogyakarta: Pustaka Pelajar, 1997)

Badri Yatim, Sejarah Peradaban Islam, Cet VII, (Jakarta: Raja Grafindo Persada, 2000) Departemen Pendidikan dan Kebudayaan, Kamus Besar Bahasa Indonesia Ibnu 'Arabi, Fusûs al-Hikam (Beirut: Dâr al-Kitab al-'Arabi, Tt)

Nurcholish Madjid, Islam Agama dan Peradaban: Membangun Makna Relevansi Doktrin Islam Dalam Sejarah (Jakarta: Paramadina, 1995) www.al.wiraja.blogspot.com/2013/02/tasawuf dan politik 